\title{
Heat Transfer and Pressure Drop Characteristics of Fin-Tube Heat Exchangers with Different Types of Vortex Generator Configurations
}

\author{
LEVENT BILIR, ${ }^{1 *}$ BARIS OZERDEM, ${ }^{1}$ \\ AYTUNC EREK, $^{2}$ \& ZAFER ILKEN ${ }^{1}$ \\ ${ }^{1}$ Department of Mechanical Engineering, İzmir Institute of Technology, \\ Urla, 35430, Izmir, Turkey \& \\ ${ }^{2}$ Department of Mechanical Engineering, Dokuz Eylül University, \\ Bornova, 35100, Izmir, Turkey
}

\begin{abstract}
A fin-and-tube heat exchanger with three different types of vortex generators is investigated in this study in order to observe the effects of these vortex generators on heat transfer and pressure drop characteristics. The individual as well as the cumulative influences of the vortex generators on the performance of a heat exchanger are examined. The numerical analyses are performed using a computational fluid dynamics (CFD) program named "Fluent". Firstly, each vortex generator type is placed at four different locations on the fin to determine its best location in terms of heat transfer and pressure drop values. After the determination of the best location on the fin for a vortex generator of each type, two different models with all three types of vortex generators are created and analyzed numerically. The investigation of the cumulative effect of three different vortex generators is the novelty of the study. The results of the study show that the use of three different vortex generators together increases heat transfer rate with a moderate increase in pressure drop value. The comparison of the present study results with an experimental and numerical study showed also a good agreement.
\end{abstract}

Key words: heat transfer, computational fluid dynamics, heat exchangers, vortex generator

\footnotetext{
*Corresponding author: L. Bilir, leventbilir@iyte.edu.tr
} 


\begin{tabular}{|llll|}
\hline \multicolumn{3}{|c|}{ NOMENCLATURE } \\
$A_{\mathrm{s}}$ & fin surface area, $\mathrm{mm}^{2}$ & $\dot{Q}$ & heat transfer rate, $\mathrm{W}$ \\
$d$ & distance from the bottom of the fin, $\mathrm{mm}$ & $t$ & fin thickness, $\mathrm{mm}$ \\
$D$ & fin tube inner diameter, $\mathrm{mm}$ & $T_{\text {fluegas,in }}$ & flue gas inlet temperature, $\mathrm{K}$ \\
$D_{\mathrm{h}}$ & hydraulic diameter, $\mathrm{mm}$ & $T_{\text {water }}$ & free stream temperature of water, $\mathrm{K}$ \\
$h_{\text {local }}$ & local convective heat transfer coefficient for fin & $V$ & velocity, $\mathrm{m} / \mathrm{s}$ \\
& surface, $\mathrm{W} / \mathrm{m}^{2} \cdot \mathrm{K}$ & $w$ & width of one tenth segment of a fin, $\mathrm{mm}$ \\
$h$ & average convective heat transfer coefficient for fin & & \\
& surface, $\mathrm{W} / \mathrm{m}^{2} \cdot \mathrm{K}$ & $\mathrm{Greek} \mathrm{symbols}$ \\
$h_{\text {water }}$ & average convective heat transfer coefficient for water & $\alpha$ & winglet angle of attack, ${ }^{\circ}$ \\
& flow, $\mathrm{W} / \mathrm{m}^{2} \cdot \mathrm{K}$ & $\delta$ & fin tube thickness, $\mathrm{mm}$ \\
$H$ & fin height, $\mathrm{mm}$ & $\mu$ & dynamic viscosity, $\mathrm{kg} / \mathrm{m} \cdot \mathrm{s}$ \\
$\dot{m}_{\text {fluegas }}$ & flue gas mass flow rate, $\mathrm{kg} / \mathrm{s}$ & $\rho$ & density, $\mathrm{kg} / \mathrm{m}^{3}$ \\
\hline
\end{tabular}

\section{INTRODUCTION}

Heat exchangers of fin-tube type have been applied to a wide variety of thermal engineering fields using systems such as air conditioning, gas heating, process cooling, etc. Fins are employed to enhance heat transfer on the gas side of gas-liquid heat exchangers. These fins act as extended surfaces and provide the heat transfer surface area for the gas side. It is known that most of the thermal resistance is on the fin side in such devices. The most popular fin pattern in heat exchanger applications is plate fin configuration due to its simplicity and rigidity. Plate fin-and-tube heat exchangers have been investigated by many researchers. In these studies, the effects of tube type and geometrical parameters were investigated numerically and experimentally. Erek et al. (2005) performed a numerical study and investigated the effect of the changes in the fin-and-tube geometry on heat transfer and pressure drop of a plate-fin heat exchanger with one-row tube configuration. The heat transfer increase was observed when the tube is placed in the downstream region and more elliptical tubes are used. They also found that for a fixed flue gas mass flow rate, lower heat transfer as well as lower pressure drop across the heat exchanger take place for a greater distance between fins. Rocha et al. (1997) made a two-dimensional heat transfer analysis in order to reveal if elliptical tubes are more feasible than circular tubes for plate-fin heat exchangers. They analyzed heat exchangers with one- and two- row tubes. They reported that elliptic tubes provide better performance. Kundu and Das (1997) determined the dimensions of a plate fin which provides the maximum heat transfer for a constant volume and different circular tube arrangements. They examined rectangular and equilateral triangular arrays for circular tubes. Abu Madi et al. (1998) tested plate and corrugated fins in a wind tunnel. Tube row number, fin thickness, the distance between fins, tubes, and tube rows were the investigated parameters. They derived correlations for the Colburn $j$ and friction factors including all the variables investigated in their study. Méndez et al. (2000) investigated the fin spacing effect on heat transfer and pressure drop values of a plate fin and circular tube heat exchanger numerically. They also performed flow visualization experiments in a water tunnel in order to investigate the flow characteristics.

In order to improve thermal performance of fins, some types of additional extended surfaces on a plate fin are applied. But during the heat enhancement process, these additional surfaces can cause an excess pressure drop because of the block effect created against gas flow. The vortices occurred around the extended surfaces and flow separation can cause a large pressure loss. The exploitation of vortex generators in heat exchangers has received a lot of attention and extensive studies have been performed, especially, in recent years. Wang et al. (2002a) conducted flow visualization observations for fin-and-tube heat exchangers with plain fin and fins having two different wave type vortex gener- 
ators using the dye-injection method. They observed that the mixing of fluid is enhanced when a vortex generator is present. Tiwari et al. (2003) investigated heat transfer and laminar flow characteristics of air in a channel with an oval tube and delta winglets. They investigated the effects of the axial location of winlets, the winglet angle of attack, the number of winlet pairs, and the Reynolds number. Wang et al. (2002b) performed flow visualization experiments in a water tunnel in order to observe the effects of annular and delta winglet vortex generators. They used the dye-injection technique for flow visualization. They also determine the pressure drop values in their experiments. They observed $10-65 \%$ higher pressure drop values than for the plain fin for the investigated cases with winglets. Kwak et al. (2003) made an experimental study investigating heat transfer and pressure drop values of finand-tube heat exchangers with different number of staggered tube rows and a winglet pair at the first row. Chen et al. (2000) investigated the effect of winglet pairs in staggered and in-line arrangements on heat transfer and pressure drop of a fin-oval tube heat exchanger numerically. They determined that the heat exchanger with staggered winglet pairs is better in terms of both heat transfer and pressure drop than the one with in-line winglets. Leu et al. (2004) analyzed heat transfer and flow over a fin and three-row tube heat exchanger with rectangular winglet vortex generators with three different winglet angles. The best winglet angle is reported as $45^{\circ}$ among the investigated cases. Lozza and Merlo (2001) carried out an experimental study on heat transfer and pressure drop performances of 15 different heat exchangers with diverse fin types (plate, wavy, louvered, and with a winglet). They reported that the plate fin with a winglet could not provide significant performance improvement and the louvered fin with a winglet provides a higher Colburn $j$ factor but also a higher friction factor compared to the similar louver fin. They also indicated that an optimization should be made for the fin with a winglet in order to improve its performance. Chen and Shu (2004) determined the effects of the delta-wing vortex generator on uniform and fan flows as well as on heat transfer. The effect of the delta wing on heat transfer performance is found to be larger for a uniform flow since the fan flow is already vortical without a delta wing. Torii et al. (2002) realized an experimental study in order to reveal delta winglet type vortex generator's effect on heat transfer and pressure drop of a three-row fin-and-circular tube heat exchanger. Their findings revealed that the configuration they proposed leads to a heat transfer increase while causes a lower pressure drop values compared to the plain fin without a winglet. Joardar and Jacobi (2005) undertook an experimental investigation in order to evaluate the thermal performance of louvered fins with delta wings. An average of $21 \%$ heat transfer coefficient increase compared to the case without a winglet was observed for the investigated air velocities in dry conditions. Sommers and Jacobi (2005) examined the effect of the delta wing vortex generator on the performance of a heat exchanger operating under frosting and dry conditions. The results for dry operating conditions showed a maximum $67 \%$ pressure drop increase. For frosting conditions, they found a $60-93 \%$ increase in the convective heat transfer coefficient. Wu and Tao (2008a) performed a numerical investigation of a laminar flow in a rectangular channel which has a punched rectangular winglet pair on one of its walls. They examined the effect of the punched hole and winglet thickness on heat transfer. They found that the punched hole increases the local Nusselt number around the hole. Another finding of the study was that when the thickness of the winglet is taken into account it affects the local Nusselt number in the near region of the winglet. A $4.1 \%$ lower average Nusselt number is encountered when the winglet thickness is taken into consideration. $\mathrm{Wu}$ and Tao (2008b) continued their numerical study and investigated the winglet pair effect on heat transfer and pressure drop for a laminar flow in a channel. They evaluated different locations on the fin for a winglet pair as well as different winglet geometric sizes and winglet shapes using the field synergy principle. Ligrani et al. (2001) investigated a channel with a dimpled wall experimentally. Two cases were taken into consideration for the other wall of the channel; a plate surface and a surface with protrusions which have the same shape as dimples. Enhanced heat transfer characteristics were observed for the channels with protrusions. Elyyan et al. (2008) realized direct and large eddy simulations of a fin with staggered dimples and protrusions, which are aligned to each other. They reported that the pressure drop because of the presence of protrusions is small at low Reynolds numbers.

The numerical and experimental studies show that vortex generators result in an enhancement of heat 
transfer with a moderate addition of pressure drop, if effective utilization is considered. The most common type of vortex generators studied in the numerical and experimental investigations were winglet, louver, imprint (dimple), and wave types. However, it is noticed that the effects of only one type vortex generator are investigated in the studies performed up until now. In this study, focus is made on three different vortex generator types, namely balcony, imprint, and winglet type. The individual as well as the cumulative influences of these vortex generators on heat transfer and pressure drop values of a fin-and-tube heat exchanger are examined in this study. The investigation of the cumulative effect of three vortex generators is the novelty of this study. Numerical investigation of twelve different fins, four with balcony, the other four with imprint, and the rest four with a winglet type vortex generator, is performed. The location of the vortex generators is varied for each type in order to observe the effect of the position of a specific vortex generator on heat transfer and pressure drop across the heat exchanger. The best probable two configurations including all three types of vortex generators are determined according to the result of this numerical investigation. These two promising configurations are modeled and investigated, numerically, and finally the best configuration is determined.

\section{DEFINITION AND MODELING OF THE ANALYZED FINS}

\subsection{Model Description}

The plate fin and circular tube heat exchanger with vortex generators under analysis is shown in Fig. 1. The schematic view of a fin model, with imprint, used in the numerical investigations is shown in Fig. 2 for illustration. Because of the symmetrical conditions, one tenth segment of the actual fins is modeled and used in the numerical calculations.

The studied models contain two fins with half fin thickness, fin tube, tube cover, and flue gas which passes through the fins as illustrated in Fig. 3. The flue gas, which passes through the fins, is represented by a volume which is extended in the y direction at the inlet and exit sides. The extensions for the inlet and exit sides are 20 and $15 \mathrm{~mm}$, respectively, as shown in Fig. 3 . The aim of these extensions is to enable more accurate boundary condition application.

The fins used for each vortex generator type have the same fin height $(H=40 \mathrm{~mm})$, fin thickness $(t=$ $0.4 \mathrm{~mm})$, and circular fin tube dimensions $(D=16.5$ $\mathrm{mm}, \delta=0.6 \mathrm{~mm}$ ). The tube cover thickness is the same as the fin thickness since it is the part of the fin which encloses the fin tube. The balcony and imprint vortex generators are located at the middle of the fin

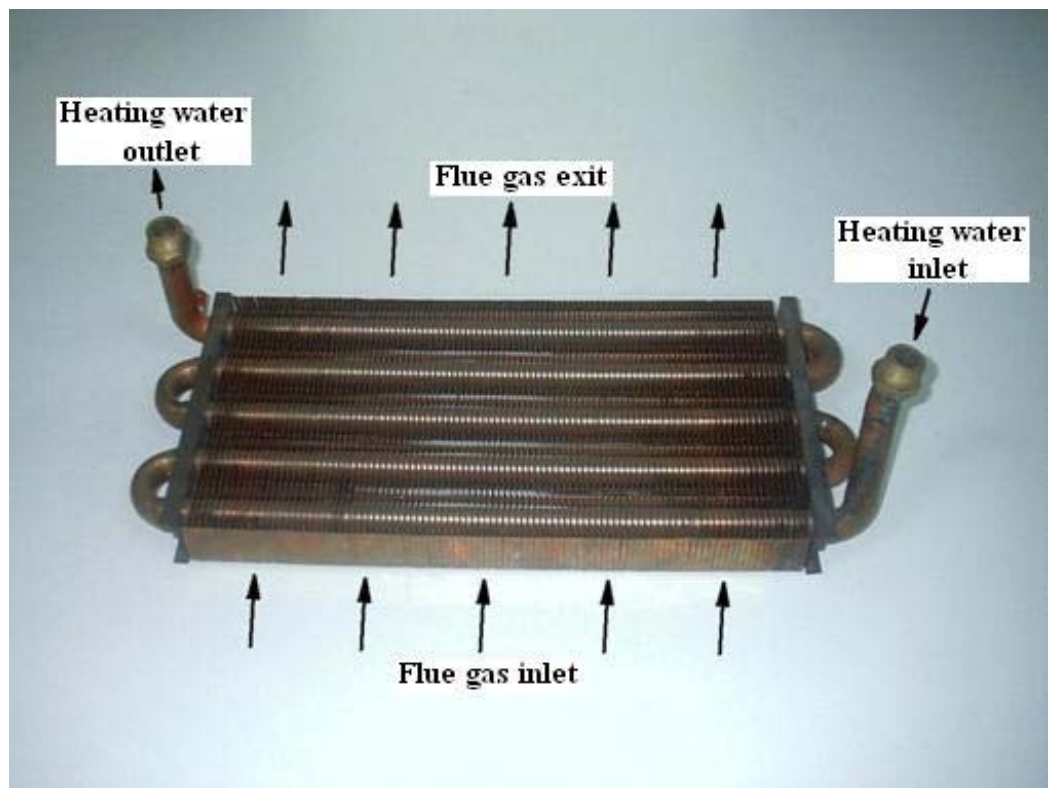

FIGURE 1. View of the heat exchanger under analysis. 


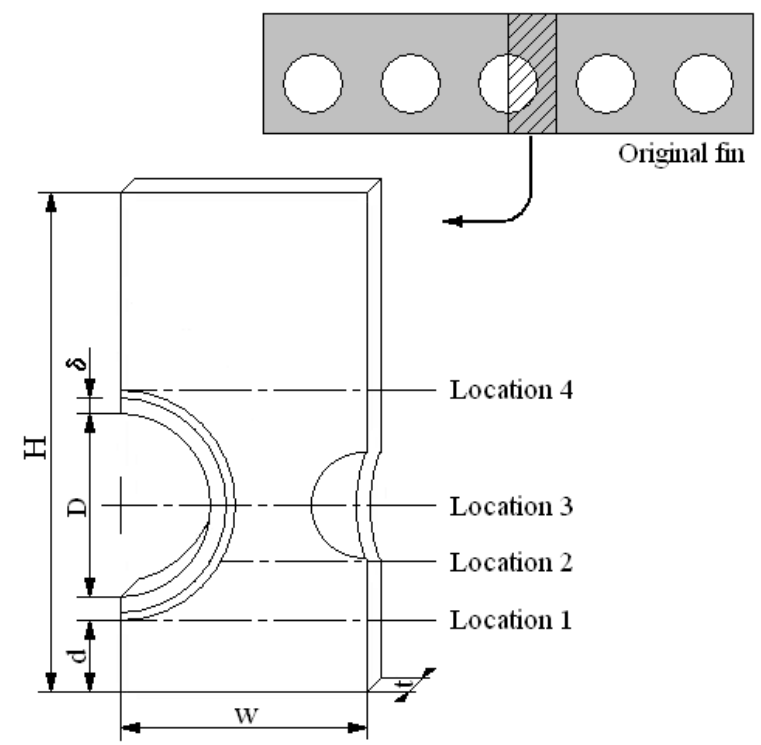

FIGURE 2. Schematic view of a fin model.

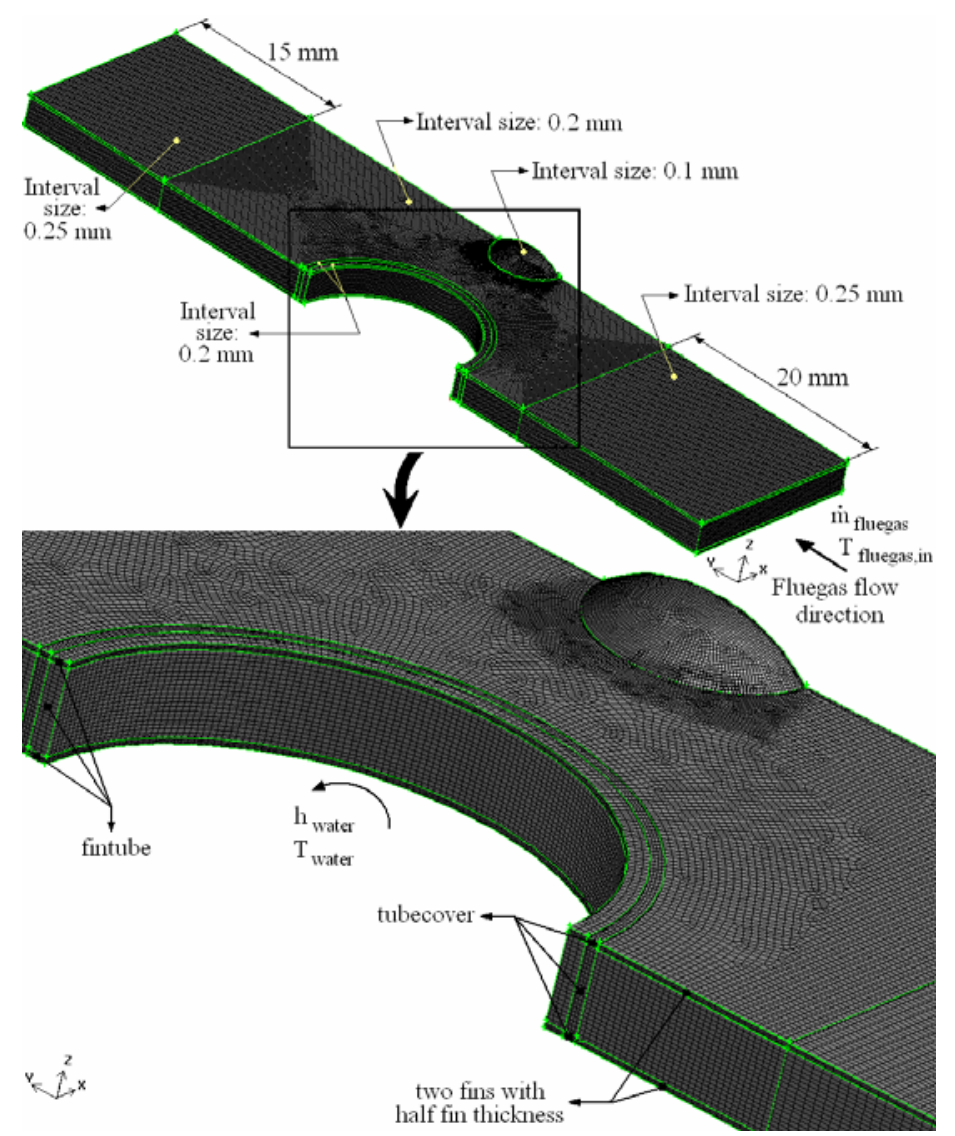

FIGURE 3. A model meshed with hexahedral finite volume elements. 

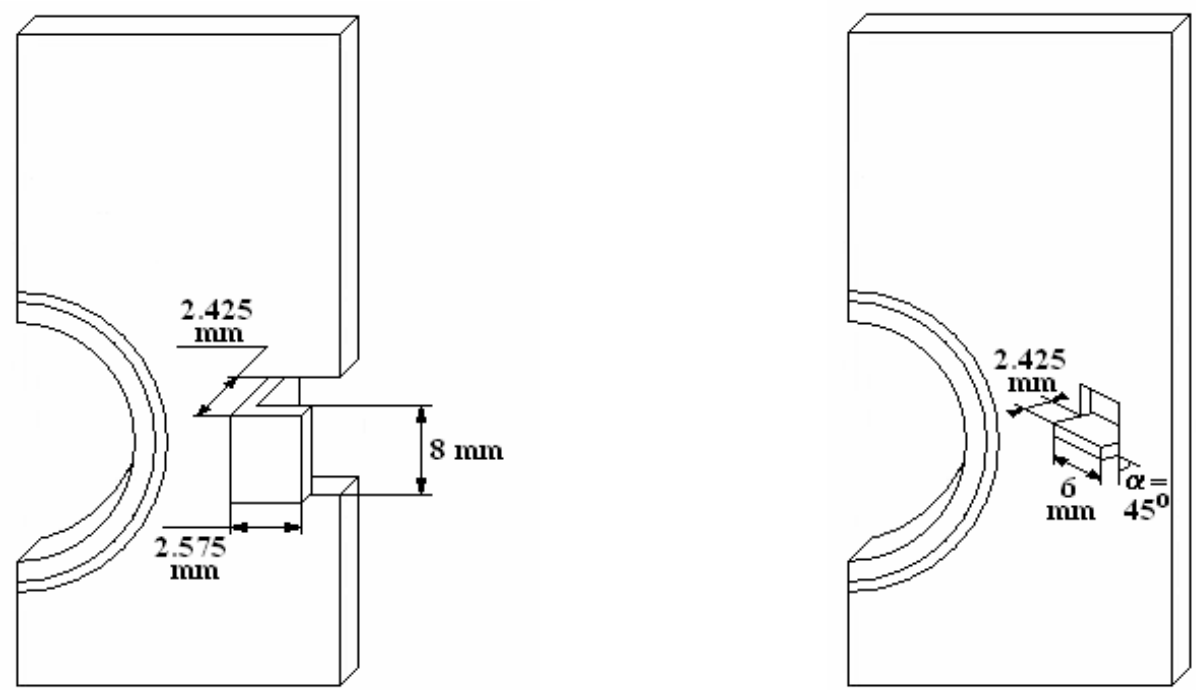

(a)

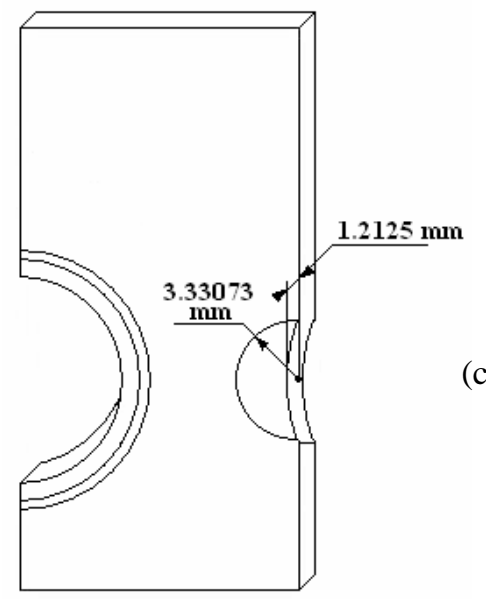

FIGURE 4. The dimensions of (a) balcony, (b) winglet and (c) imprint.

TABLE 1. Model Names and Location of Vortex Generators

\begin{tabular}{|c|c|c|c|c|c|c|c|c|c|c|c|c|c|c|c|}
\hline \multirow[t]{3}{*}{$\begin{array}{c}\text { Loca- } \\
\text { tion }\end{array}$} & \multirow{3}{*}{$\begin{array}{l}\text { Distance from } \\
\text { the bottom of } \\
\text { the fin, } \\
\boldsymbol{d}(\mathrm{mm})\end{array}$} & \multicolumn{4}{|c|}{ Fins with balcony } & \multicolumn{4}{|c|}{ Fins with imprint } & \multicolumn{4}{|c|}{ Fins with winglet } & \multicolumn{2}{|c|}{$\begin{array}{l}\text { Fins with } \\
\text { balcony, } \\
\text { imprint, and } \\
\text { winglet }\end{array}$} \\
\hline & & \multicolumn{4}{|c|}{ Model name } & \multicolumn{4}{|c|}{ Model name } & \multicolumn{4}{|c|}{ Model name } & \multicolumn{2}{|c|}{ Model name } \\
\hline & & B1 & B2 & B3 & B4 & I1 & $\mathrm{I} 2$ & $\mathrm{I} 3$ & I4 & W1 & $\mathrm{W} 2$ & W3 & W4 & WBI & WBI \\
\hline 1 & 6.25 & B & & & & I & & & & $\mathrm{W}$ & & & & I & B \\
\hline 2 & 10.875 & & $\mathrm{~B}$ & & & & $\mathrm{I}$ & & & & $\mathrm{W}$ & & & & \\
\hline 3 & 15.5 & & & $\mathrm{~B}$ & & & & I & & & & $\mathrm{W}$ & & B & I \\
\hline 4 & 24.75 & & & & $\mathrm{~B}$ & & & & I & & & & $\mathrm{W}$ & $\mathrm{W}$ & $\mathrm{W}$ \\
\hline
\end{tabular}


tube pitch $(w=17.5 \mathrm{~mm})$, while a winglet type vortex generator is located at a distance determined by a radius of $13 \mathrm{~mm}$ around the fin tube. The fin pitch value is $3 \mathrm{~mm}$ for all investigated cases. The dimensions of the three different vortex generators are presented in Fig. 4.

The vortex generators are located at four different locations in order to determine the best location of each vortex generator type in terms of heat transfer and pressure drop values. The summary of the models under evaluation is presented in Table 1.

As an example, for the model B1, there is a balcony (B) at location 1, which is $6.25 \mathrm{~mm}$ away from the bottom of the fin, while for the model WBI, imprint (I) which is at location 1 , balcony (B) which is at location 3 , and winglet (W) which is at location 4 are present on the fin. Location 1 coincides with the bottom point of the tube cover, while location 3 coincides with the center of the fin tube, and location 4 coincides with the upper point of the tube cover as shown in Fig. 2. Location 2 is the middle point of locations 1 and 3 .

Hexahedral finite volume elements are generated for each model as can be seen from Fig. 3. Different numbers of finite volume elements are tested in order to ensure the grid independence of the solution. It is found that the use of 20 elements for the flue gas volume in between two fins and 4 elements along the half fin thickness for the fin volumes is appropriate to obtain a numerically stable solution. The volume meshes are generated by creating face meshes and applying a cooper algorithm to the volume. The cooper algorithm projects the meshes of a face of the volume to the other face. The interval size values for all faces are illustrated in Fig. 3. As a result, 850,000 or more control volumes are generated for each model depending on the fin geometry. Scaled residuals for velocities, continuity, and energy equations are observed to be less than $10^{-4}, 10^{-7}$, and $10^{-7}$ for the converged numerical results. Similar scaled residual values were obtained for all investigated models.

\subsection{Boundary Conditions and Material Properties}

The flue gas flow is in the $+y$ direction as illustrated in Fig. 3. The bottom surface of the model is the entrance of flue gas. The temperature of flue gas at the entrance surface $\left(T_{\text {fluegas,in }}\right)$ is defined as $1500 \mathrm{~K}$, while the flue gas mass flow rate $\left(\dot{m}_{\text {fluegas }}\right)$ is taken as $1.904 \times 10^{-5}$ $\mathrm{kg} / \mathrm{s}$. These values are taken from an actual combi boiler apparatus application. The exhaust of flue gas is from the top surface of the model, and outflow boundary condition is defined for this surface. Side, front, and back surfaces of the model are defined as symmetrical boundaries as well. The inside surface of the fin tube is defined as wall, and the water flow inside the fin tube is simulated by defining convective heat transfer for this wall. Free stream temperature of water $\left(T_{\text {wa- }}\right.$ ter) is taken as $343 \mathrm{~K}$ and the convective heat transfer coefficient $\left(h_{\text {water }}\right)$ is calculated as $9100 \mathrm{~W} / \mathrm{m}^{2} \cdot \mathrm{K}$ using the Gnielinski correlation given by Eq. (1) (Kakaç and Yener, 1995).

$$
N u=\frac{(f / 2)(\operatorname{Re}-1000) P r}{1+12.7(f / 2)^{1 / 2}\left(\operatorname{Pr}^{2 / 3}-1\right)}
$$

where

$$
f=(1.58 \ln R e-3.28)^{-2}
$$

The heat exchanger is assumed to be made of copper and the thermophysical properties of copper are taken as constant. The flue gas flow through the fins is assumed to be laminar as the Reynolds number for the flue gas flow is low. The flow is also assumed to be incompressible and steady.

The Reynolds number for the flue gas flow is calculated as follows (Incropera et al., 2007)

$$
R e=\frac{\rho V D_{h}}{\mu}
$$

Since the inlet temperature of flue gas is $1500 \mathrm{~K}$ and the exit temperature of flue gas is found to be around $450-500 \mathrm{~K}$, the average flue gas temperature can be assumed as $1000 \mathrm{~K}$. The density of flue gas is taken as $0.3482 \mathrm{~kg} / \mathrm{m}^{3}$ which is the density of air at $1000 \mathrm{~K}$. Similarly, dynamic viscosity for $1000 \mathrm{~K}$ is $424.4 \times 10^{-7} \mathrm{~kg} / \mathrm{m} \cdot \mathrm{s}$ and the corresponding Prandtl number is 0.726 . The velocity value is taken as 4.24 $\mathrm{m} / \mathrm{s}$, which is the maximum velocity value that can be encountered in the gap between two fins, and the hydraulic diameter of the channel formed by two fins is calculated as

$$
D_{h}=\frac{4 \times A}{P}
$$

The dimensions of the channel formed by two fins are $175 \mathrm{~mm}$ and $2.6 \mathrm{~mm}$. So the cross-sectional area $(A)$ and the perimeter $(P)$ of the channel is $455 \mathrm{~mm}^{2}$ 
and $355.2 \mathrm{~mm}$, respectively. As a result, the hydraulic diameter of the channel is calculated as $5.1239 \mathrm{~mm}$. The Reynolds number for the flow is also calculated from Eq. (2) as 178.25.

The one tenth segment of a fin could also be modeled by modeling the fin with whole fin thickness and the surrounding flue gas volumes on two sides of the fin. In this case, the front and back surfaces should be defined as periodic boundaries while the side surfaces remain as symmetrical boundaries. This type of models for the fins WIB and WBI are also created. As a result, it is found that the numerical results of such models and the ones of the current models differ by $0.2 \%$ (maximum) for heat transfer rate and $1.8 \%$ (maximum) for pressure drop values.

\section{VALIDATION OF THE NUMERICAL MODEL}

The numerical investigation of a plate fin-tube heat exchanger is performed using a computational fluid dynamics program named "Fluent" in the present study. However, no other study, investigating fins with the same geometrical dimensions as the fins used in the present study, is encountered in the literature. So, the fins used in a similar study ( $\mathrm{Wu}$ and Tao, 2008b), in which the effects of a winglet pair on heat transfer are investigated numerically and experimentally, are analyzed in order to accomplish validation of the current study.

The tests were conducted in a thermally isolated wind tunnel for different air velocity values in $\mathrm{Wu}$ and Tao (2008b). The experimentally tested fins consisted of two aluminum layers with 1-mm thickness and an electrical heating element with $0.15-\mathrm{mm}$ thickness in between the two aluminum layers. As the fin is symmetric, half of the fin is considered for computational domain as shown in Fig. 5. Details of the fin, winglet, and air channel dimensions can be found in $\mathrm{Wu}$ and Tao (2008b). A heating power of $35 \mathrm{~W}$ was supplied by the electrical heater element and the average convective heat transfer coefficient over the upper and lower fin surfaces (h) was determined experimentally and numerically in $\mathrm{Wu}$ and Tao (2008b). The models of the fins with the geometrical dimensions described in $\mathrm{Wu}$ and Tao (2008b) are created in the present study to accomplish the comparison of the numerical results obtained from "Fluent" software and the experimental and computational results of $\mathrm{Wu}$ and Tao (2008b). The heating power given by the electrical heater element is considered as an inner heat source for electrical heating element volume in the present model $\left(7,291,667 \mathrm{~W} / \mathrm{m}^{3}\right.$ for the plate fin and $7,481,030 \mathrm{~W} / \mathrm{m}^{3}$

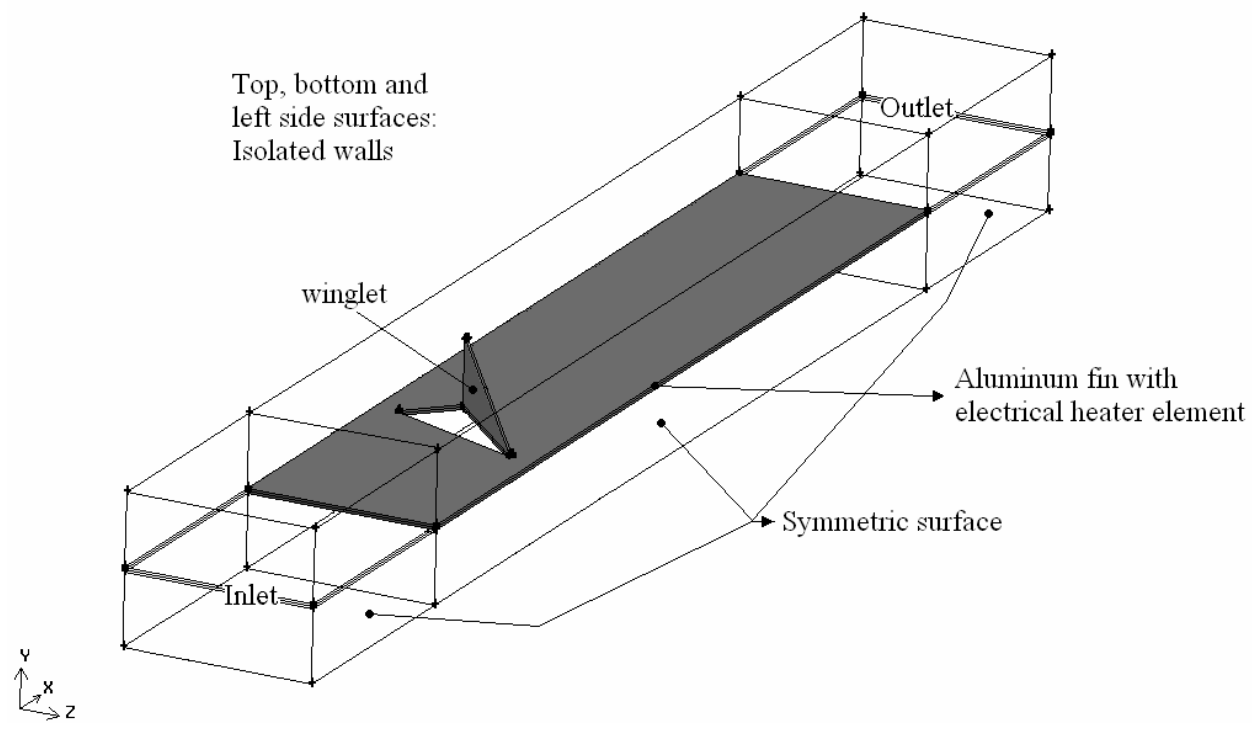

FIGURE 5. The schematic view of the computational model of the fin with a winglet investigated by Wu and Tao (2008b). 


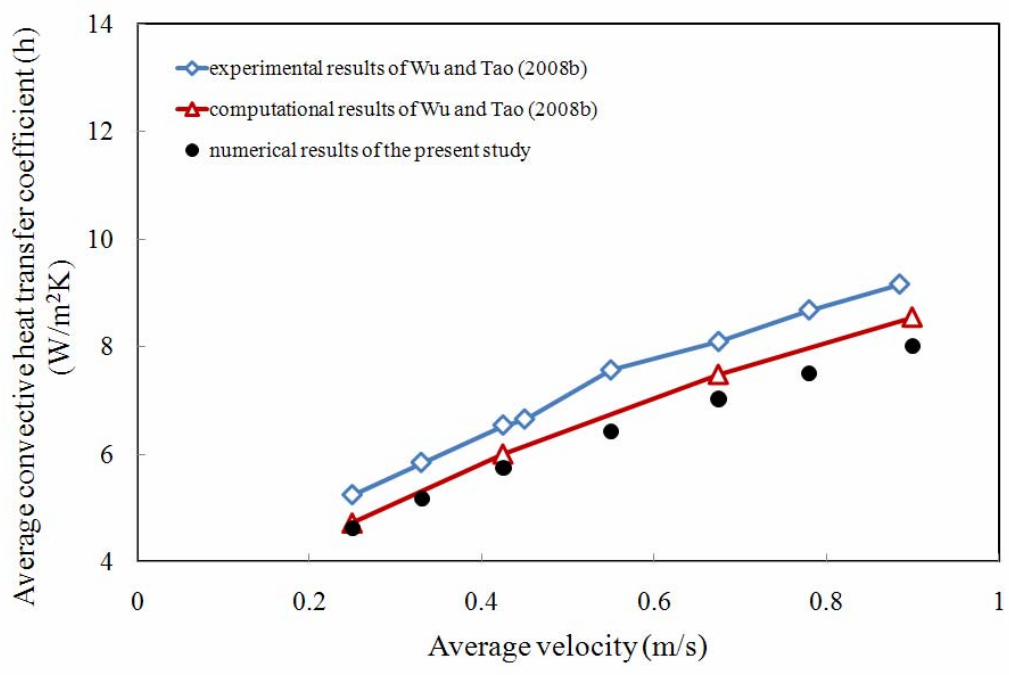

(a)

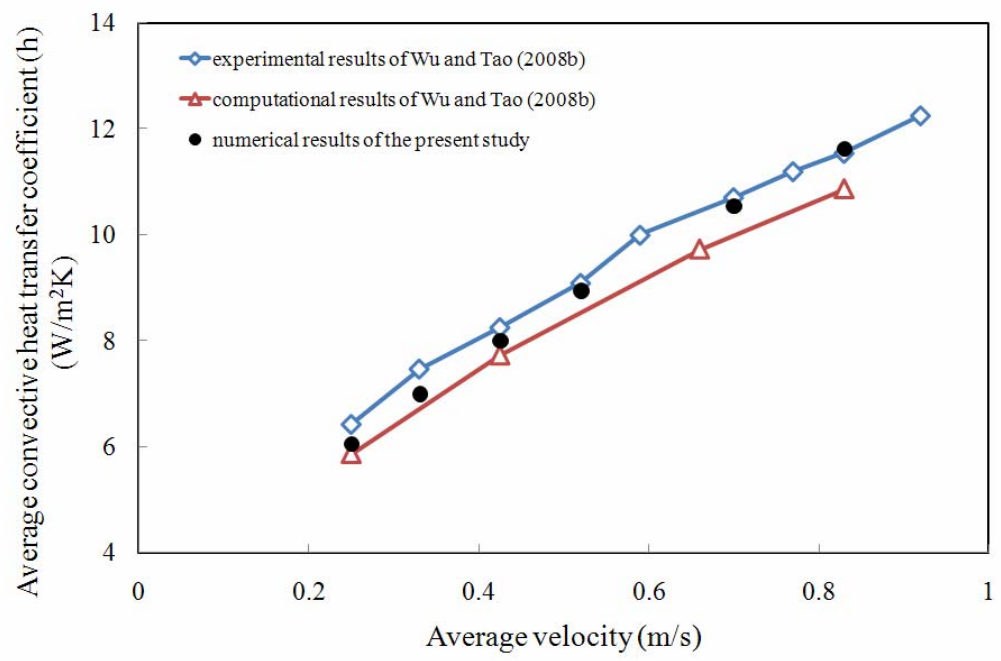

(b)

FIGURE 6. Comparison of the numerical results of the present study with the results of Wu and Tao (2008b): (a) for a plate fin; (b) for the fin with winglet with a $45^{\circ}$ angle of attack

for the fin with a winglet). The difference of the inner source values stems from the fact that there is a punched winglet hole in the model of the fin with a winglet and this winglet hole changes the volume of the electrical heater element compared to the case of a plate fin. Since the winglet angle of attack is taken as $45^{\circ}$ in the present study, the fin with the same winglet angle attack is taken into consideration for the comparison with the results of $\mathrm{Wu}$ and Tao (2008b). As the number of control volumes is limited with the available computer source, approximately 1,200,000 control volume elements for a plate fin and 1,760,000 control volume elements for the fin with a winglet are used in the analysis. The total control volume elements used for the analysis of the fins investigated in the present study are less than the values of the models used for comparison purpose. However, since the geometrical dimensions of the fins investigated in $\mathrm{Wu}$ and Tao (2008b) are considerably greater than the ones of the fins examined in the present study and the wind tunnel 
dimensions are significantly greater than the channel formed by two fins investigated in this study, the mesh quality for the fins investigated in the present study is noticeably finer. The average convective heat transfer coefficient results obtained from the numerical analysis are compared with the experimental and computational results of Wu and Tao (2008b) in Fig. 6. In the "Fluent" program, the local convective heat transfer coefficient values are calculated as given in Eq. (4) and the average convective heat transfer coefficient is calculated as shown in Eq. (5)

$$
\begin{gathered}
q=h_{\text {local }}\left(T_{\text {wall }}-T_{\text {flue gas }}\right) \\
h=\frac{1}{A_{\mathrm{s}}} \int_{A_{\mathrm{s}}} h_{\text {local }} d A_{\mathrm{s}}
\end{gathered}
$$

It can be seen that there is a good agreement between the results of the present study and the ones of $\mathrm{Wu}$ and Tao (2008b) for both the plate fin and the fin with a winglet cases. It is concluded that, since finer meshes are employed for the analysis of the fins in the present study and the use of coarser meshes in the comparison part of the study shows a satisfactory agreement with the results of $\mathrm{Wu}$ and Tao (2008b), the numerical results obtained for the analysis of the fins in the present study are reliable.

\section{RESULTS AND DISCUSSION}

Twelve different fins, which are grouped according to their vortex generator type, are modeled as described in Table 1 . Then, the heat transfer and fluid flow problems are solved, numerically, to obtain the total heat transfer rate of the heat exchanger and the pressure drop value of flue gas as it passes across the heat exchanger. A plain fin model (model P) with the same dimensions as the other fins with vortex generator is also investigated numerically to determine the effect of each vortex generator type. The heat transfer and pressure drop values of the plain fin are taken as $100 \%$ and the normalized values of the other models are calculated accordingly. The heat transfer rate of a single fin is also presented as well as the heat transfer rate of the modeled segment. The fin heat transfer rate corresponds to ten times the segment heat transfer rate as the modeled segment is one tenth of a single fin. The numerical results are tabulated in Table 2 .

As a result of numerical simulations, it is concluded that the best location in terms of heat transfer values for all vortex generator types is location 4, which coincides with the level of tube cover upper point. Moreover, it is found that this is the only location which results in a higher heat transfer rate compared to the plain fin for the fin with a winglet. The placement at location 4 also results in a minimum total pressure drop value for the model with a winglet. The lower heat transfer value found for the fin with a winglet is due to the low Reynolds number of the flue gas flow. At low Reynolds numbers the winglet type vortex generator could not achieve a heat transfer increase, because it could not generate vortices strong enough to provide heat transfer enhancement. In this case, the area behind the winglet cannot contribute to the heat

TABLE 2. Numerical Results of Heat Transfer and Pressure Drop Across the Heat Exchanger

\begin{tabular}{|c|c|c|c|c|c|c|}
\hline & $\begin{array}{c}\text { Model } \\
\text { name }\end{array}$ & $\begin{array}{c}\dot{\boldsymbol{Q}} \text { (per } \\
\text { segment) (W) }\end{array}$ & $\begin{array}{c}\dot{\boldsymbol{Q}} \text { (per fin) } \\
(\mathrm{W})\end{array}$ & $\begin{array}{c}\text { Normalized } \\
\dot{\boldsymbol{Q}}(\%)\end{array}$ & $\begin{array}{c}\text { Total pressure } \\
\text { drop (Pa) }\end{array}$ & $\begin{array}{c}\text { Normalized total } \\
\text { pressure drop }(\%)\end{array}$ \\
\hline & $\mathrm{P}$ & 24.3413 & 243.413 & 100 & 4.0833 & 100 \\
\hline \multirow{4}{*}{$\begin{array}{c}\text { Fins with } \\
\text { balcony }\end{array}$} & $\mathrm{B} 1$ & 24.4065 & 244.065 & 100.267 & 4.5201 & 110.697 \\
\cline { 2 - 7 } & $\mathrm{B} 2$ & 24.4390 & 244.390 & 100.401 & 4.7194 & 115.578 \\
\cline { 2 - 7 } & $\mathrm{B} 3$ & 24.4669 & 244.669 & 100.516 & 4.8049 & 117.672 \\
\hline \multirow{3}{*}{$\begin{array}{c}\text { Fins with } \\
\text { imprint }\end{array}$} & $\mathrm{B} 4$ & 24.6013 & 246.013 & 101.068 & 4.5776 & 112.105 \\
\cline { 2 - 7 } & $\mathrm{I} 1$ & 24.3907 & 243.907 & 100.203 & 4.1877 & 102.557 \\
\cline { 2 - 7 } & $\mathrm{I}$ & 24.4116 & 244.116 & 100.289 & 4.2497 & 104.075 \\
\hline
\end{tabular}




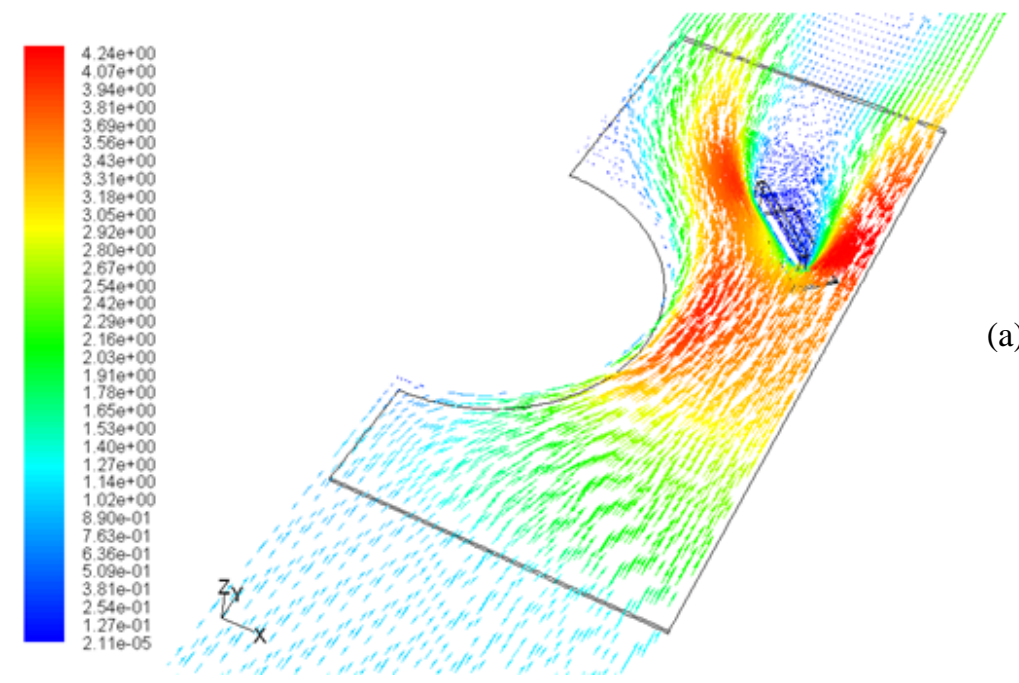

(a)

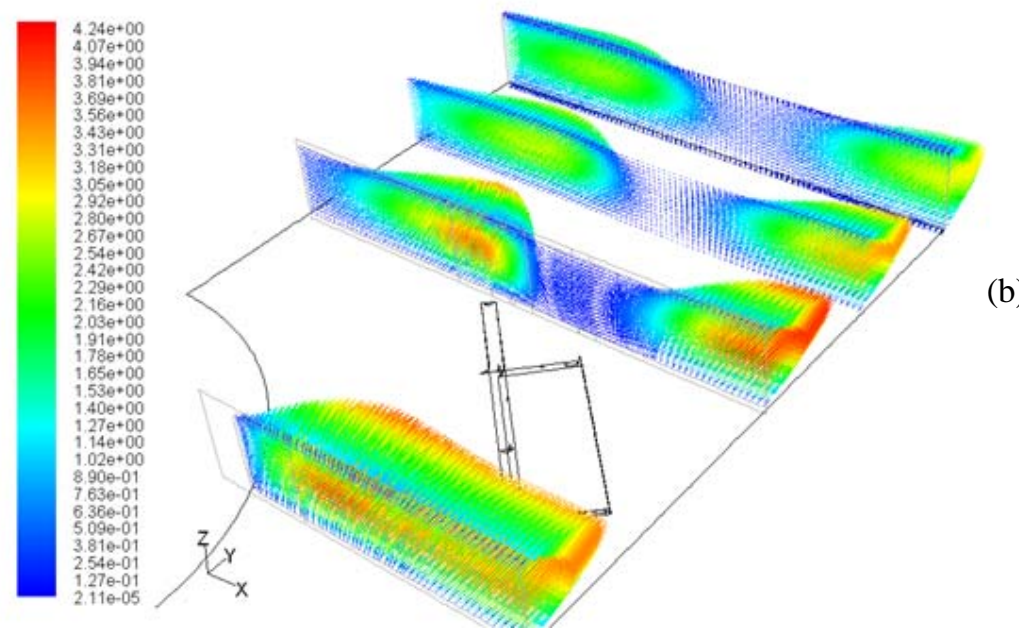

(b)

FIGURE 7. (a) Velocity vectors at the surface crossing the winglet for model W4; (b) Velocity vectors at different horizontal cross sections for model W4.

TABLE 3. Heat Transfer and Pressure Drop Values of the Fins with Three Types of Vortex Generators

\begin{tabular}{|c|c|c|c|c|c|}
\hline Model name & $\begin{array}{c}\dot{\boldsymbol{Q}} \\
\text { (per segment) } \\
(\mathrm{W})\end{array}$ & $\begin{array}{c}\dot{\boldsymbol{Q}} \\
\text { (per fin) (W) }\end{array}$ & $\begin{array}{c}\text { Normalized } \\
\dot{\boldsymbol{Q}}(\%)\end{array}$ & $\begin{array}{c}\text { Total pressure } \\
\text { drop (Pa) }\end{array}$ & $\begin{array}{c}\text { Normalized total } \\
\text { pressure drop }(\%)\end{array}$ \\
\hline P & 24.3413 & 243.413 & 100 & 4.0833 & 100 \\
\hline WBI & 24.7808 & 247.808 & 101.806 & 5.7613 & 141.094 \\
\hline
\end{tabular}




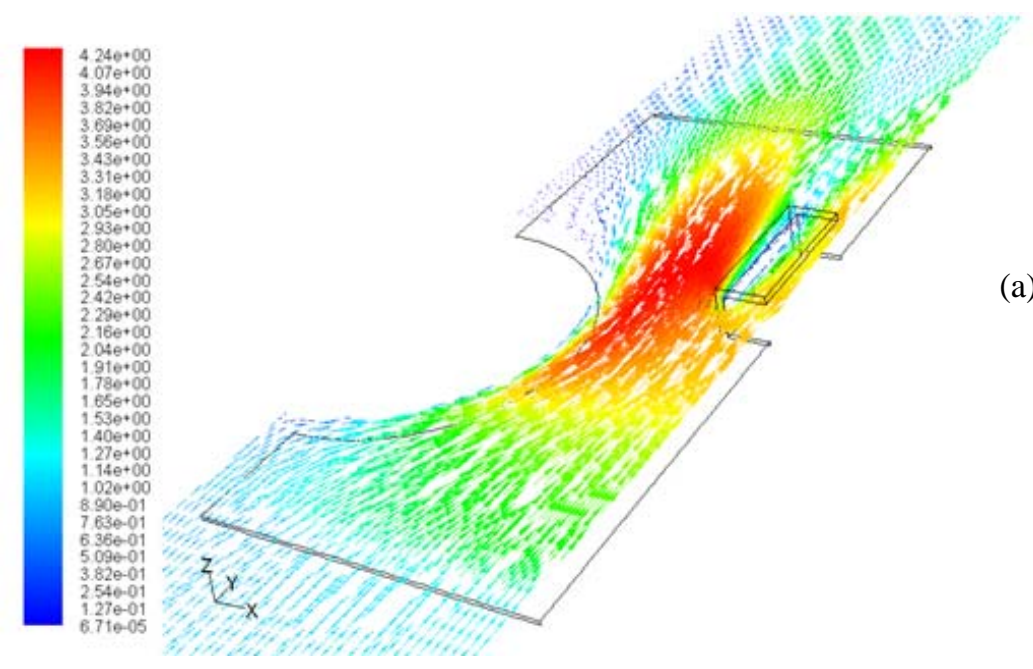

(a)

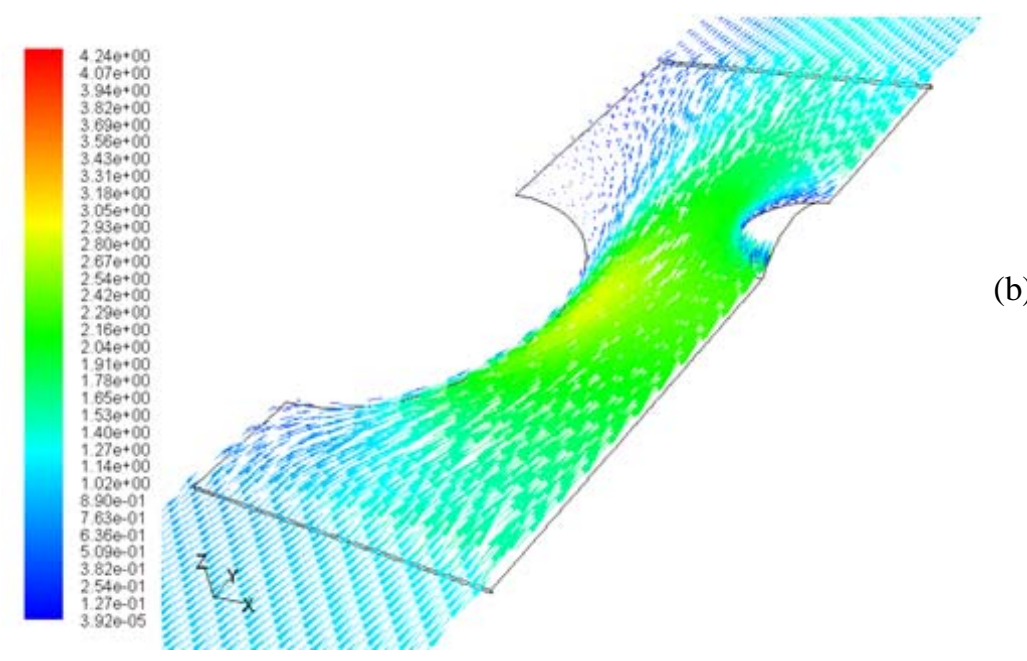

FIGURE 8. (a) Velocity vectors at the surface crossing the balcony for model B4; (b) Velocity vectors at the surface crossing the imprint for model 14.

transfer process since the flue gas velocity is decreased and lower heat transfer values than plain fin are encountered. However when it is placed at location 4, it directs the flow to the tube wake zone besides generating vortices and enhances the heat transfer. The velocity vectors at the surface crossing the winglet at location 4 are given in Fig. 7. The velocity vectors at the surfaces crossing the balcony and the imprint placed at location 4 are also shown in Fig. 8. As it can be seen from these two figures, winglet and balcony accelerate the flow more than the imprint and consequently highest heat transfer enhancement is obtained from the fin with a balcony, followed by the fin with a winglet, and the fin with an imprint, respectively. It is also found that total pressure drop values for locations 1 and 4 are approximately the same for balcony and imprint type vortex generators. Locations 2 and 3 cause higher pressure-drop values for all types, especially for the one with a winglet type vortex generator. The reason of this outcome can be explained with the decrease in the flow cross-sectional area because of the presence of a fin tube. As a result of these conclusions, it is decided to model two different fins with all three different vortex generators (model WBI and model 
WIB) in order to investigate more efficient fins using all vortex generators. The winglet type vortex generator is placed at location 4 for both fin models, as this location results in best performance in terms of both heat transfer and pressure drop values for winglet. For one fin model (model WBI), the balcony type vortex generator, while for the other model (model WIB), the imprint type vortex generator is placed at location 3 . Finally, the imprint type vortex generator for model WBI and the balcony type vortex generator for model WIB are placed at location 1 . Location 1 is chosen for the last type vortex generator, because heat transfer values for the fins with the imprint or balcony type vortex generator do not show great difference when an imprint or a balcony is placed at location 1 or 2 . However, higher pressure drop values are encountered at location 2. Finally, the models of two fins with winglet, imprint, and balcony are created and the numerical results obtained for these models are given in Table 3.

The results of numerical solutions for these two fins show that the use of all three types of vortex generators together results in better heat transfer performance than the use of only one type. But, it also causes higher pressure-drop values. When the two fins with three types of vortex generators are compared with each other, it is seen that model WBI shows better heat transfer performance than model WIB. However, it is also observed that the pressure drop value of model WBI is slightly higher than that of model WIB.

\section{CONCLUSIONS}

In the present study, the effects of imprint, balcony, and winglet type vortex generators on heat transfer as well as total pressure drop across the heat exchanger are investigated numerically. As a conclusion, it is observed that the use of all vortex generators can lead to an increase in heat transfer performance of a heat exchanger on condition that their locations are appropriately chosen. If the placement is not made appropriately, a vortex generator can also have an adverse effect on heat transfer. An example of this situation is encountered for fins with winglet type vortex generators in this study. Another important conclusion of the study is that all types of vortex generators cause an increase in pressure drop value. But, the location has also an important effect on pressure drop characteristic. As a final conclusion, it is found that the heat transfer performance of both models with three types of vortex generators is better than the ones with one type vortex generator and the pressure-drop value increase due to the three vortex generators is moderate.

\section{REFERENCES}

Abu Madi, M., Johns, R. A., and Heikal, M. R., Performance characteristics correlation for round tube and plate finned heat exchangers, Int. J. Refrig., vol. 21, no. 7, pp. 507-517, 1998.

Chen, Y., Fiebig, M., and Mitra, N. K., Heat transfer enhancement of finned oval tubes with staggered punched longitudinal vortex generators, Int. J. Heat Mass Transfer, vol. 43, pp. 417-435, 2000.

Chen, T. Y. and Shu, H. T., Flow structures and heat transfer characteristics in fan flows with and without delta-wing vortex generators, Exp. Thermal Fluid Sci., vol. 28, pp. 273-282, 2004.

Elyyan, M. A., Rozati, A., and Tafti, D. K., Investigation of dimpled fins for heat transfer enhancement in compact heat exchangers, Int. J. Heat Mass Transfer, vol. 51, pp. 2950-2966, 2008.
Erek, A., Özerdem, B., Bilir, L., and İken, Z., Effect of geometrical parameters on heat transfer and pressure drop characteristics of plate fin and tube heat exchangers, Appl. Thermal Eng., vol. 25, pp. 2421-2431, 2005.

Incropera, F. R., De Witt, D. P., Bergman, T. L., and Lavine, A. S., Fundamentals of Heat and Mass Transfer, 6th ed., River Street, Hoboken, N.J.: John Wiley and Sons, Ch. 8, p. 487, 2007.

Joardar, A. and Jacobi, A. M., Impact of leading edge delta-wing vortex generators on the thermal performance of a flat tube, louvered-fin compact heat exchanger, Int. J. Heat Mass Transfer, vol. 48, pp. 1480-1493, 2005.

Kakaç, S. and Yener, Y., Convective Heat Transfer, 2nd ed., Florida, Boca Raton: CRC Press, Begell House, Ch. 9, p. 294, 1995. 
Kundu, B. and Das, P. K., Optimum dimensions of plate fins for fin-tube heat exchangers, Int. J. Heat Fluid Flow, vol. 18, pp. 530-537, 1997.

Kwak, K. M., Torii, K., and Nishino, K., Heat transfer and pressure loss penalty for the number of tube rows of staggered finned-tube bundles with a single transverse row of winglets, Int. $J$. Heat Mass Transfer, vol. 46, pp. 175-180, 2003.

Leu, J. S., Wu, Y. H., and Jang, J. Y., Heat transfer and fluid flow analysis in plate-fin and tube heat exchangers with a pair of block shape vortex generators, Int. J. Heat Mass Transfer, vol. 47, pp. 4327-4338, 2004.

Ligrani, P. M., Mahmood, G. I., Harrison, J. L., Clayton, C. M., and Nelson, D. L., Flow structure and local Nusselt number variations in a channel with dimples and protrusions on opposite walls, Int. J. Heat Mass Transfer, vol. 44, pp. 4413-4425, 2001.

Lozza, G. and Merlo, U., An experimental investigation of heat transfer and friction losses of interrupted and wavy fins for fin-and-tube heat exchangers, Int. J. Refrig., vol. 24, pp. 409-416, 2001.

Méndez, R. R., Sen, M., Yang, K. Y., and McClain, R., Effect of fin spacing on convection in a plate fin and tube heat exchanger, Int. J. Heat Mass Transfer, vol. 43, pp. 39-51, 2000.

Rocha, L. A. O., Saboya, F. E. M., and Vargas, J. V. C., A comparative study of elliptical and circular sections in one and two row tubes and plate fin heat exchangers, Int. J. Heat Fluid Flow, vol. 18, pp. 247-252, 1997.

Sommers, A. D. and Jacobi, A. M., Air-side heat transfer enhancement of a refrigerator evaporator using vortex generation, Int. J. Refrig., vol. 28, pp. 1006-1017, 2005.

Tiwari, S., Maurya, D., Biswas, G., and Eswaran, V., Heat transfer enhancement in cross-flow heat exchangers using oval tubes and multiple delta winglets, Int. J. Heat Mass Transfer, vol. 46, pp. 2841-2856, 2003.

Torii, K., Kwak, K. M., and Nishino, K., Heat transfer enhancement accompanying pressure-loss reduction with winglet-type vortex generators for fintube heat exchangers, Int. J. Heat Mass Transfer, vol. 45, pp. 3795-3801, 2002.

Wang, C. C., Lo, J., Lin, Y. T., and Liu, M. S., Flow visualization of wave-type vortex generators having inline fin-tube arrangement, Int. J. Heat Mass Transfer, vol. 45, pp. 1933-1944, 2002a.

Wang, C. C., Lo, J., Lin, Y. T., and Wei, C. S., Flow visualization of annular and delta winlet vortex generators in fin-and-tube heat exchanger application, Int. J. Heat Mass Transfer, vol. 45, pp. 3803-3815, 2002b.

Wu, J. M. and Tao, W. Q., Numerical study on laminar convection heat transfer in a rectangular channel with longitudinal vortex generator. Part A: Verification of field synergy principle, Int. J. Heat Mass Transfer, vol. 51, pp. 1179-1191, 2008a.

Wu, J. M. and Tao, W. Q., Numerical study on laminar convection heat transfer in a channel with longitudinal vortex generator. Part B: Parametric study of major influence factors, Int. J. Heat Mass Transfer, vol. 51, pp. 3683-3692, 2008 b. 